\title{
A educação para o civismo e o patriotismo no Colégio Triângulo Mineiro de Uberaba (Minas Gerais, Brasil) nas décadas de 1940 e 1950
}

\author{
Edilene Alexandra Leal Soares \\ Universidade Federal do Triângulo Mineiro \\ Giseli Cristina do Valle Gatti \\ Universidade de Uberaba
}

\section{Resumo}

presente artigo analisa as práticas cívico-patrióticas, desenvolvidas no Colégio Triângulo Mineiro de Uberaba (Minas Gerais, Brasil), nas décadas de 1940 e 1950, com foco privilegiado nas festas escolares e nos eventos esportivos. Para abordar essa temática, foram utilizados importantes referenciais teóricos, tais como, Da Matta (1 997), Nóbrega (1 952), Cândido (2007), Vaz (2007), Souza (2008) e Julia (200 1 ). As fontes utilizadas na investigaçãopertenciam ao Arquivo Público de Uberaba, à Superintendência Regional de Ensino de Uberaba e ao Memorial Mário Palmério. Faz-se uma reflexão sobre a cultura e as práticas escolares, detendo-se nos eventos cívicos e patrióticos, notadamente, as festas escolares. Em seguida, examina-se a forma tomada pelas atividades esportivas e de suas relações com o civismo e o patriotismo. Conclui-se pela observação do alto nível de correspondência entre o ideal cívico-patriótico estatal posto na época com o efetivado no âmbito das práticas escolares no Colégio Triângulo Mineiro.

Palavras-chave: Instituição escolar. Civismo. Patriotismo.

\section{Education for civic responsibility and patriotism at the Colégio Triângulo Mineiro of Uberaba (Minas Gerais, Brazil) in the 1940s and 1950s}

\begin{abstract}
Analysis of the civic-patriotic practices developed at the Colégio Triângulo Mineiro de Uberaba (Minas Gerais, Brazil) in the 1940s and 1950s, with a special focus on school parties and sporting events. To approach this theme, important theoretical references were used, such as Da Matta (1997), Nóbrega (1952), Cândido (2007), Vaz (2007), Souza (2008), and Julia (2001). The sources used during the investigation belong to the Arquivo Público de Uberaba (Uberaba Public Archives), to the Superintendência Regional de Ensino de Uberaba (Uberaba Regional Office of Education), and to the Memorial Mário Palmério (Mário Palmério Memorial). This study begins with a reflection
\end{abstract}


on culture and school practices, with an emphasis on civic and patriotic events, most notably school parties. After that, the form assumed by sports activities is examined and their relationship to civil responsibility and patriotism. It concludes with observation of the high level of correspondence between the government civic-patriotic ideal established at that time and that carried out in the environment of school practices in the Colégio Triângulo Mineiro.

Keywords: School institution. Civic responsibility. Patriotism.

\section{La educación para el civismo y el patriotismo en el Colegio Triangulo Minero de Uberaba (Minas Gerais, Brasil) en las décadas de 1940 y 1950}

\section{Resumen}

Análisis de las practicas cívico-patrióticas desarrolladas en el Colegio Triangulo Minero de Uberaba (Minas Gerais, Brasil), en las décadas de 1940 y 1950, con foco privilegiado en las fiestas escolares y en los eventos deportivos. Para tratar esta temática fueron utilizados importantes referenciales teóricas como, Da Matta (1 997), Nóbrega (1952), Cândido (2007), Vaz (2007), Souza (2008) e Julia (200 1). Las fuentes accionadas durante la investigación pertenecían al Archivo Público de Uberaba, a la Superintendencia Regional de Enseñanza de Uberaba y al Memorial Mário Palmério. Se parte de la reflexión sobre la cultura y las practicas escolares, deteniéndose en los eventos cívicos y patrióticos, notadamente, las fiestas escolares. En seguida, se examina la forma tomada por las actividades deportivas y sus relaciones con el civismo y el patriotismo. Se concluye por la observación, el alto nivel de correspondencia entre el ideal cívico-patriótico estatal puesto en la época y el efectuado en el ámbito de las prácticas escolares en el Colegio Triangulo Minero.

Palabras clave: Institución escolar. Civismo. Patriotismo.

A criação do Colégio Triângulo Mineiro coincide no tempo, com o regime político do Estado Novo no Brasil, com seu viés autoritário muito presente e com a educação e os meios de comunicação de então muito utilizados como meio de propaganda política. O Colégio nasce, a princípio, com a denominação de Liceu do Triângulo Mineiro, permanecendo com essa denominação até 1942, quando requereu inspeção prévia para oferecer o $1^{\circ}$ ciclo do ensino secundário - o Ginasial. Assim, apenas no ano de 1943, o Colégio obteve sua inspeção preliminar para funcionar como Ginásio, sendo que, por 
meio da publicação do Decreto n 21.901 , de 7 de outubro de 1946, obteve a inspeção permanente para o $1^{\circ}$ ciclo do Ensino Secundário - o Ginasial. Cabe salientar que, após a publicação do Decreto n²2.523, de 27 de janeiro de 1947, o Ginásio Triângulo Mineiro recebeu autorização para funcionar como Colégio Triângulo Mineiro.

É válido observar que o recorte temporal escolhido para analisaras práticas relacionadas às festividades cívico-patrióticas na instituição escolar compreendeu as décadas de 1940 e de 1950, época marcada por grande efervescência de valores cívicos, para o que foi acionado, sobretudo, um corpus documental que comportou jornais locais e acervo fotográfico. Essas fontes foram analisadas com base em aportes teórico-metodológicos consubstanciados na perspectiva da história das instituições educativas. Nesse sentido, Justino Magalhães assevera que:

Compreender e explicar a existência histórica de uma instituição educativa é, sem deixar de integrá-la na realidade mais ampla que é o sistema educativo, contextualizá-la, implicando-a no quadro de evolução de uma comunidade e de uma região, é por fim sistematizar e (re) escrever-the o itinerário de vida na sua multidimensionalidade, conferindo um sentido histórico (MAGALHÃES, 1999, p. 64).

Cabe ressaltar que essas festividades faziam parte do contexto escolar, visto que envolviam professores, alunos, corpo administrativo e a própria direção do estabelecimento de ensino. Nessa perspectiva, pode-sereportar à Julia (200 1), que compreende que essas atividades podem ser parte de uma cultura escolar, destacando que cada escola desenvolve seus hábitos e rotinas, fazendo, assim, com que cada uma tenha a sua própria identidade. Assim, tomando Julia (2001) como referência, pode-se descrever a cultura escolar como,

[...] um conjunto de normas que definem conhecimentos a ensinar e condutas a inculcar, e um conjunto de práticas que permitem a transmissão desses conhecimentos e a incorporação desses comportamentos; normas e práticas coordenadas a finalidades que podem variar segundo as épocas (finalidadesreligiosas, sociopolíticas ou simplesmente de socialização) (UULIA, 200 1, p. 10). 
Dessa maneira, o Colégio Triângulo Mineiro esteve inserido emdeterminados valores e condutas e procurou disseminá-los aos seus discentes, uma vez que as festividades tinham caráter pedagógico, demonstrando a ideia de educação integral, que perpassa, também, pelos valores da sociedade da época. Nesse sentido, Vaz (2006) explica que as escolas tornavam-se instrumentos para difundir a civilidade e ordem no País. Segundo a autora, a preparação para os eventos cívico-patrióticos contribuiriam para essa civilidade, portanto "A festa instaura a alegria, legitima o regime e rememora as obrigações e contributos para aqueles que fazem parte do país". Dessa forma, "A festa instaura uma nova ordem e, neste sentido, em momentos autoritários, ela mostra o regime como a nova ordem preestabelecida" (VAZ, 2006, p. 43). A esse propósito, Gatti explica que,

A escola é concebida não só como um espaço de disseminação de conhecimentos, mas também em sentido mais amplo de produção e transmissão de cultura, valores e normas que são aplicados tanto no espaço interno da escola, quanto perante a sociedade. Historicamente, essa instituição constrói uma cultura e estabelece uma identidade única, com maior ou menor aproximação ao contexto no qual está inserida, criando assim, uma imagem frente à sociedade, por meio de suas práticas cotidianas que são efetivadas por seus agentes (professores, administradores, alunos e funcionários), estabelecendo, desse modo, importante papel no desenvolvimento da sociedade (GATTI, 2010, p. 188).

Nessa perspectiva, ficou evidente que o Colégio Triângulo Mineiro, além de disseminar conteúdos disciplinares, também colaborava, sobremaneira, para a formação de uma consciência cívico-patriótica relacionada à ideologia estatal vigente, contribuindo, assim, para difundir valores, considerados ideais para a população uberabense e brasileira. Alguns exemplos já podem ser mencionados, visando evidenciar melhor essa constatação, tais como os eventos e as atividades desenvolvidas concernentes às comemorações do Dia da Independência do Brasil, e, também, as práticas esportivas e à comemoração da data de aniversário da instituição. Assim, existiam ritos e intenções que não estavam explícitos para as pessoas que acompanhavam aquelas comemorações, contudo havia o propósito de disseminar normas que contribuiriam para a ordemdesejada pelo Estado naquele período. 
Segundo Vaz (2006, p. 43), as comemorações cívico-patrióticas constituíram uma "[...] das formas mais características de propaganda política no Estado Novo [...]" sendo que, para ele, aquelas festas representavam verdadeiros "[...] palcos de exaltação nacionalista, tentando esconder os conflitos no próprio interior das relações políticas, para legitimar a ordem existente".

Em Uberaba, os eventos patrióticos eram assistidos por muitas pessoas e aconteciam na parte central da cidade, sendo a escola e suas atividades, nessas ocasiões, instrumentos utilizados para projetar e, possivelmente, introjetar os valores e as condutas condizentes com o que estava preconizado pelo Estado, estabelecendo, assim, o que as pessoas precisavam para ser cidadãs detentoras de amor e de respeito à pátria.

Salienta-se, ainda, que, além dos valores patrióticos tão enfatizados a partir do Estado Novo, o culto ao corpo, à sua vitalidade, como um instrumento a serviço da pátria, era outro fator que assinalava a relevância da prática de atividades físicas. Isso corroborava a utilização dos eventos esportivos na e pela escola, demonstrando à população a necessidade de colocá-los em prática. $\bigcirc$ Colégio Triângulo Mineiro inseriu seus discentes em atividades tanto cívico-patrióticas quanto esportivas e, nesse aspecto, percebe-se que toda essa dinâmica de atividades foi também estendida à sociedade, como forma não só de demonstrar a excelência do Colégio para essa formação integral da juventude que ali estudava, mas também para imbuir, na sociedade uberabense, o patriotismo.

Para a análise das práticas relacionadas às festividades cívico-patrióticas do Colégio Trângulo Mineiro de Uberaba nas décadas de 1940 e 1950, o artigo está estruturado em duas partes. Na primeira, discorre-se sobre as festividades cívico-patrióticas promovidas no Colégio Triângulo Mineiro de Uberaba. Na segunda parte, são abordados os eventos esportivos destinados à formação da juventude estudantil.

\section{Festas escolares no Colégio Triângulo Mineiro de Uberaba}

De acordo com Candido (2007), as festas escolares têm um caráter pedagógico, o que pode ser evidenciado desde a escolha das datas que figuram no calendário escolar até o conteúdo que estará presente no programa de 
comemorações, chegando, inclusive, a influenciar as formas de agir e de se comportar no momento da solenidade.

Constata-se, também, que os rituais festivos escolares trazem uma dimensão política e um cunho patriótico muito forte, que ajudam a perpetuar a ideia do progresso, da civilidade e da ordem instaurada em determinado momento histórico. Schemes (1995) afirma que a festa cívica reforça a imagem de poder, comemorando a morte do passado - o velho e a instauração do novo - futuro.

Nessa perspectiva, pode-se afirmar que as festas escolares eram carregadas de intencionalidade, ou seja, não apenas projetavam a escola para a sociedade, mas também disseminavam valores para a coletividade, reforçando a ideia de amor à pátria e a exaltação aos símbolos nacionais.

Cabe ressaltar, ainda, que a imprensa também foi corresponsável pela propagação desses valores patrióticos, enaltecendo a importância desses eventos e aclamando a juventude como portadora desses ideais cívico-patrióticos, além de disseminar essa relevante postura perante a pátria.

Na cidade de Uberaba, verifica-se esse movimento da imprensa no sentido de enfatizar as atividades de cunho patriótico, a exemplo do que acontecia em todo o País, sobretudo no que se refere às comemorações do Dia da Independência, consideradas relevantes e que eram divulgadas na imprensa local, no caso de Uberaba, representada pelojornal Lavoura e Comércio.

$\bigcirc$ presidente Vargas pronunciou, ontem, importantíssimo discurso. [...] É preciso manter alertados os espíritos, é preciso que o patriotismo exalte os nossos sentimentos e a disciplina das nossas atividades se torne cada vez mais estreita e mais firme [...] /COMO UBERABA COMEMOROU O DIA DA PÁTRIA, 1941 , p. 2).

Getúlio Vargas impunha, como condição para a ordem do País, a imprescindível missão de manter os valores preconizados pelo Estado Novo. Assim, a nação permaneceria pacífica e detentora de valores essenciais ao povo brasileiro. Os desfiles cívicos seriam a expressão dos valores consagrados pelo Estado Novo. O jornal Lavoura e Comércio (UBERABA comemorou, de modo brilhante, o Dia da Pátria [...], 1941, p. 6) destaca um desses momentos na cidade: "Uberaba comemorou de modo brilhante o Dia da Pátria, realizando sessões cívicas e brilhantes paradas pelas ruas da cidade". $\bigcirc$ mesmo jornal ainda detalhava a programação e mencionava que "[... ] no $4^{\circ}$ Batalhão 
do Comando Militar e no Tiro de Guerra 168 foram realizadas bonitas reuniões em suas sedes falando, nesta ocasião, vários oradores sobre a efeméride da independência". Apesar de nesse período já haver ocorrido a fundação do Colégio Triângulo Mineiro, na época ainda conhecido como Liceu do Triângulo Mineiro, não foi mencionado se ele participou daquele desfile. Contudo, não tardaria para a instituição, fundada por Mário de Assunção Palmério, participar daqueles atos patrióticos.

Convém mencionar, nesse momento do trabalho, que Mário de Assunção Palmério nasceu em $1^{\circ}$ de março de 1916, na cidade de Monte Carmelo, em Minas Gerais, com formação em Matemática. Em 1940, inaugurou o Liceu Triângulo Mineiro e, após a expansão das atividades educacionais, a instituição recebeu a denominação de Ginásio e, posteriormente, Colégio Triângulo Mineiro. Em 1972, inaugura-se nova fase e surgem as Faculdades Integradas de Uberaba (FIUBE), que, em 1988, transformaram-se na Universidade de Uberaba (UNIUBE). Salienta-se que Mário Palmério foi deputado federal e escritor de obras como Vilas dos Confins, Chapadão do Bugre e O Morro das Setes Voltas. Seu falecimento ocorreu em 24 de setembro de 1996.

Conforme mencionado, o jornal Lavoura e Comércio, principal veículo de informação da cidade, divulgava, em primeira página, os atos cívicos e, em 1942, a manchete destacava que,

O presidente Vargas falará hoje ao mundo. Todo o Brasil comemora hoje, com estrondosas manifestações civicas e patrioticas, a magna data de nossa independencia. O presidente Vargas falará hoje ao mundo, às 15 horas, durante a grande concentração cívica que terá lugar no estadio de São Januário (UBERABA VIVE HOJE UM DE SEUS MAIS GLORIOSOS DIAS CIVICOS, 1942, p. 11.

Em todo o País, o 7 de Setembro era comemorado, exaltando o patriotismo do Estado Novo:

A oração do presidente Vargas nunca teve a ressonância historica que terá na tarde de hoje. Cerca de 25 mil escolas, sob a regência do maestro Vila Lobos, interpretarão varias canções patrioticas, durante a 'Hora da Independencia' (UBERABA VIVE HOJE UM DE SEUS MAIS GLORIOSOS DIAS CIVICOS, 1942, p. 1). 
A educação para o civismo e o patriotismo no Colégio Triângulo Mineiro de Uberaba nas décadas de 1940 e 1950

De acordo com Da Matta (1997), o 7 de Setembro é um dos rituais mais comemorados no Brasil, somente comparado ao Carnaval e à Semana Santa. Da Matta afirma, ainda, que

Nesse sentido, o tempo do Dia da Pátria é único, acentuando o rompimento definitivo com o período colonial e o início da maioridade política. É pois, um rito histórico de passagem, já que sua performance visa não só recriar um momento glorioso do passado, mas muito especialmente a marcar a passagem entre o mundo colonial e o mundo da liberdade, da autodeterminação. Desse modo os eventos históricos e empiricamente registrados são tomados como paradigmáticos e os personagens que o engendram, como heróis nacionais oficiais (DA MATTA, 1997, p. 54).

Assim, as escolas tornavam-se meios para difundir a civilidade e ordem no País. Nessa perspectiva, Vaz (2006, p. 90) explica que "O dia 7 de Setembro, comemoração da Independência do Brasil, foi uma das datas cívicas mais celebradas, principalmente no período do Estado Novo, tendo a escola como um dos principais centros das realizações festivas".

Ainda reportando às notícias dos desfiles cívicos na cidade, o jornal Lavoura e Comércio (1942, p. 1) citou, em manchete, que "Uberaba vive hoje um de seus mais gloriosos dias cívicos" destacando a participação de toda a sociedade e evidenciando a organização e a imponência das escolas que desfilaram naquele dia.

Em Uberaba, o evento acontecia na parte central da cidade, na Praça Rui Barbosa, em frente ao Paço Municipal, e contava com a presença de inúmeras pessoas que assistiam às apresentações do $4^{\circ}$ Batalhão do Comando Militar, com a "[...] refinada banda desta garbosa corporação militar, que deu grande realce à solenidade, ao lado da 'Corporação Musical Uberabense' do maestro Benedito Nascimento" (Lavoura e Comércio, Uberaba vive hoje um de seus mais gloriosos dias civicos, p. 11.

O jornal registrou, ainda, que o "Tiro de Guerra 168, sob o comando do $1^{\circ}$ Sargento Teófilo Lamounier, também deu uma nota de muito garbo à expressiva cerimônia". Todo esse ritual, com suas intenções subjacentes, era disseminado à população que presenciava o evento, sendo as escolas as legítimas representantes desses preceitos, por meio dos atos cívicos, e também 
das práticas esportivas, como, por exemplo, em 1943, quando ocorreram as comemorações de aniversário da instituição,

aniversário do Liceu Triângulo, que obedece á esclarecida orientação do sr. prof. Mário Palmério, moço de grandes predicados pessoais e espirito progressista desenvolvido, comemorou sabado ultimo, o seu terceiro ano de bons e proficuos serviços prestados á causa da instrução e da educação da nossa mocidade. Comemorando esta grata efeméride, o Liceu organizou uma bonita passeata com os seus alunos do Centro de Instrução Pré-Militar, os quais desfilaram com muito garbo e disciplina pelas principais ruas de nossa cidade ostentando o seu alvo uniforme de paradas e transportando a bandeira nacional e o pavilhão do educandario. O magnifico desfile teve para ainda maior brilhantismo, o concurso valioso da afinada banda do $4^{\circ}$ B.C.M, de Uberaba. Grande número de pessoas correu ás sacadas de nossos prédios e as janelas de nossas residências particulares, a-fim-de apreciar aquele espetáculo, digno de ser visto pela magnífica impressão causada e pela nota distinta da perfeita organização técnica e física do renomado estabelecimento de ensino uberabense. Nossos parabéns ao prof. Mário Palmério e nossos votos de prosperidade para sua progressista casa de instrução (O ANIVERSÁRIO DO LICEU DO TRIÂNGULO MINEIRO, 1943, s/p).

O jornal enalteceu o desfile do então Liceu do Triângulo, contudo o que chama a atenção é que não se tratava de comemoração do Dia da Independência, mas do aniversário da instituição, celebrado junto à população com toda uma simbologia que remete aos valores patrióticos. Assim, os olhares voltaram-se para aquela ação de civilidade e respeito que a escola demonstrava àcidade de Uberaba. Eram ritos e intenções que corroboravam os valores preconizados no período, e, ainda, dava visibilidade à instituição educativa.

Segundo Fonseca (2012, p. 10), o Colégio Triângulo Mineiro também participava de outras comemorações cívicas como o Centenário de Castro Alves e o Dia de Tiradentes e isso evidenciava o "[...] culto dos homens que souberam engrandecer a pátria brasileira". Nessa mesma perspectiva, Vaz (2006, p. 97) explica que os eventos destacavam os nomes de figuras eminentes do País, o que contribuía para enaltecer "o culto aos grandes heróis do Brasil". Assim, o Colégio Triângulo Mineiro participou de desfiles cívicos que chamavam a atenção da população uberabense que se aglomerava em 
avenidas e praças, no intuito de prestigiar tais eventos. Vale ressaltar que esses eventos, também, eram importantes para a comunidade escolar que apresentava a parada patriótica com visível elegância, destacando-se perante a sociedade, pela disciplina, civilidade e patriotismo. Cabe salientar que as paradas cívicas também eram fundamentais para incentivar a população, valorizar a pátria em conformidade com os valores vigentes no contexto social, político e cultural do país. Vaz (2006) comenta sobre a importância desses eventos promovidos pelas escolas,

A escola, para o Brasil, seria modelo de conduta, amor e sacrifício patriótico, fazendo dos jovens e das crianças um exemplo para que a pátria pudesse ser educada. $O$ imaginário construído da criança que nasce e estuda num Brasil 'novo' reforçava o papel da escola e da educação como formadoras da nação, utilizando as comemorações cívicas como canais úteis de exteriorização da criança e da escola para o restante da sociedade (VAZ, 2006, p. 94).

Ademais, era um ritual que permitia enaltecer o trabalho desenvolvido na instituição, identificando-a junto a outros estabelecimentos de ensino, que também estavam presentes naqueles momentos. Nesse sentido, a atividade da educação física contribuía para o bom desempenho dos alunos durante os eventos cívicos. De acordo com documentos encontrados no acervo da Superintendência Reginal de Ensino (SER) de Uberaba, a organização para a participação do colégio, nessas atividades, era de responsabilidade do Prof. Teófilo Lamounier. Ele era diplomado pela Escola de Educação Física do Exército do Rio de Janeiro e estava à frente da disciplina de Educação Física no Colégio. De acordo com Vaz,

As paradas cívicas nas datas comemorativas denotama importância que o corpo físico exerce como metáfora do corpo da nação. A educação física era obrigatória para que a criança e o jovem obtivessem uma saúde equilibrada, tornando-se 'sadios' e resistentes (VAZ, 2006, p. 102). 
Figura 1

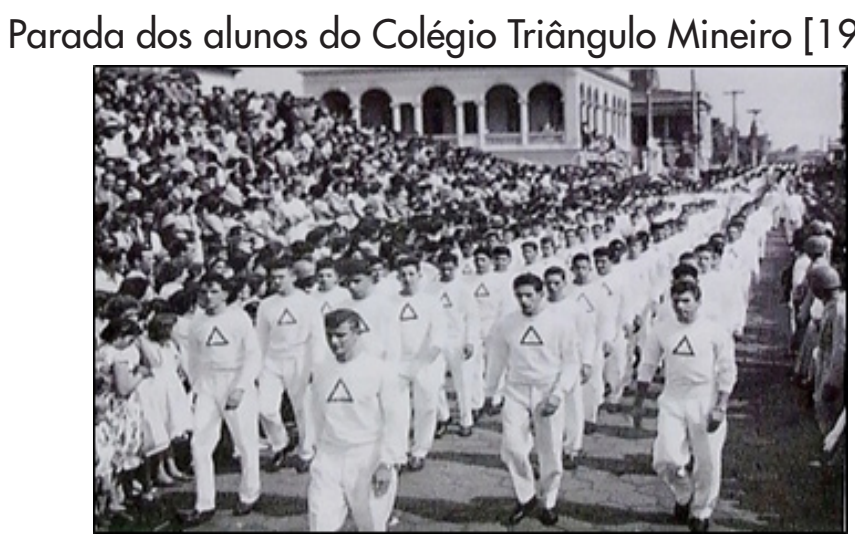

Fonte | Superintendência Regional de Ensino de Uberaba (Minas Gerais)

Nessa perspectiva, os desfiles do Colégio Triângulo Mineiro apresentavam a organização e imponência que as paradas requeriam dos alunos. As vestimentas impecáveis e desfilando de forma harmônica, denotando a ordem e o respeito, desenvolvendo a estética corporal para aquelas atividades. Essas solenidades atraíam toda a comunidade, deixando explícita a importância e o papel desenvolvido pela escola, em que era reafirmada a sua identidade e seu prestígio social. Assim, a centralidade da instituição escolar na formação da juventude da cidade evidenciava-se, não apenas no interior da unidade escolar, mas também, na forma como atingia a população do município, disseminando conteúdos que interessavam ao Estado brasileiro, sobretudo àqueles relacionados à legislação educacional da época e aos pressupostos ideológicos nela contidos, em especial, à ideia de unidade nacional, centralização estatal e patriotismo. 
Figura 2

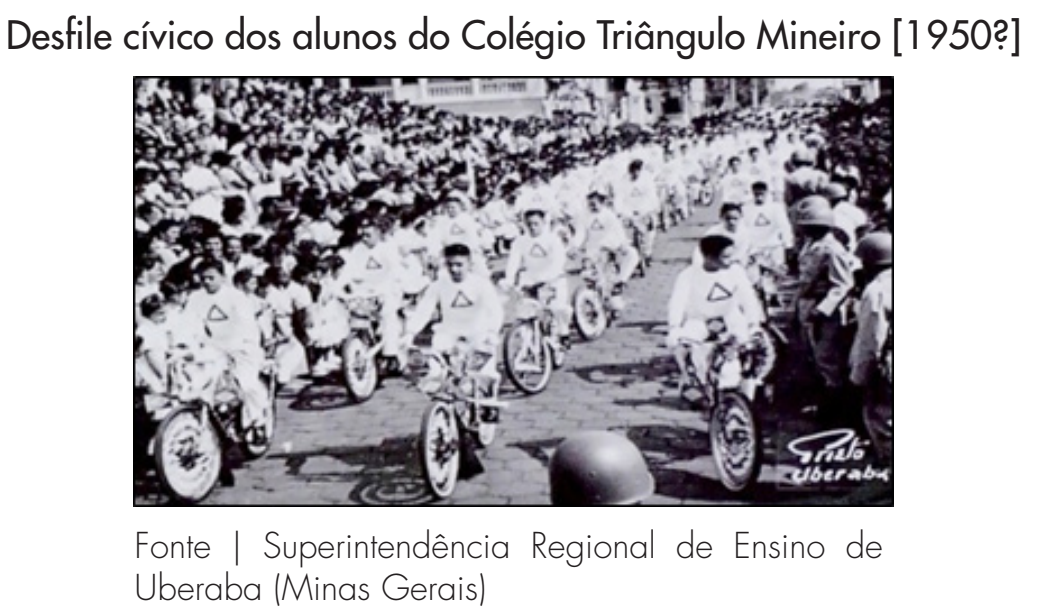

A Figura 2 traz a imagem dos alunos em desfile,com bicicletas, o que denota uma prática que incentivava os costumes de hábitos saudáveis devendo, consequentemente, ser estendidos ao público. Nesse sentido, percebe-se que o Colégio Triângulo Mineiro proporcionava aos alunos atividades que compreendiam tanto intenções cívicas como também um ideal de cidadãos sadios. Assim, pode-se afirmar que o colégio atendia aos princípios colocados por Capanema a partir da Portaria 467, de 16 de julho de 1943, que revela o caráter educativo das atividades físicas que ele chamava de "educação patriótica", que tinha "[...] por finalidade a formação da consciência patriótica" uma vez que estava destinado à preparação "[...] dos homens portadores das concepções e atitudes espirituais que é preciso infundir nas massas, que é preciso tornar habituais entre o povo [...]", por isso, era primordial concebê-lo como um "[...] ensino patriótico por excelência [...] capaz de criar, no espírito das gerações novas, a consciência da responsabilidades diante dos valores maiores da pátria, a sua independência, a sua ordem, o seu destino" (NÓBREGA, 1952, p. 311 ).

Nas Figuras 3 e 4, podem ser observados desfiles dos alunos do Colégio Triângulo Mineiro, sendo possível notar, primeiramente, a presença de cavalos, típicos na região, e, depois, de um aluno que porta a bandeira nacional, a qual é considerada símbolo do patriotismo, respeito e manutenção da ordem e valores cívicos. Observa-se que a escola tinha o compromisso de disseminar esse amor à pátria e reforçar o nacionalismo como maneira 
de estabelecer a coesão da população brasileira. Fonseca (2012, p. 10) menciona que, em 7 de setembro de 1944, os alunos da instituição educativa de Mário Palmério realizaram desfiles, ratificando o compromisso do estabelecimento com os valores da pátria brasileira. De acordo com o autor, houve "[...] a demonstração cabal do esforço que se desenvolve no Ginásio Triângulo Mineiro, em prol da educação cívica da nossa juventude".

Figura 3

Desfile cívico dos alunos do Colégio Triângulo Mineiro [1950?]

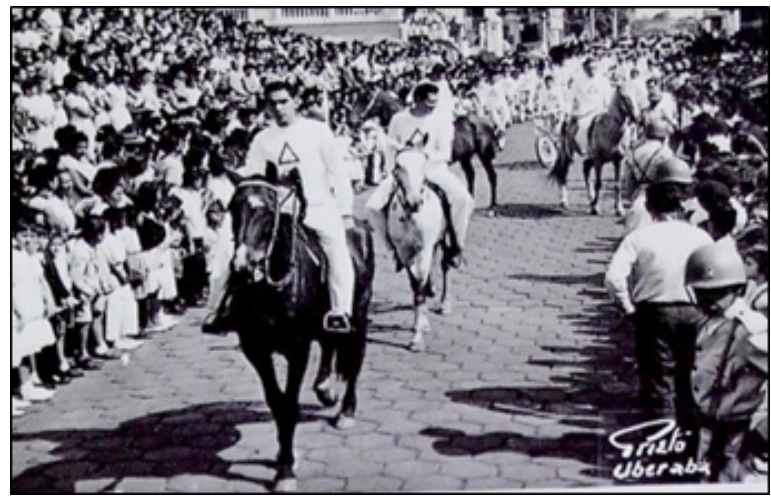

Fonte | Superintendência Regional de Ensino de Uberaba (Minas Gerais)

Figura 4

Desfile cívico dos alunos do Colégio Triângulo Mineiro [1950?]

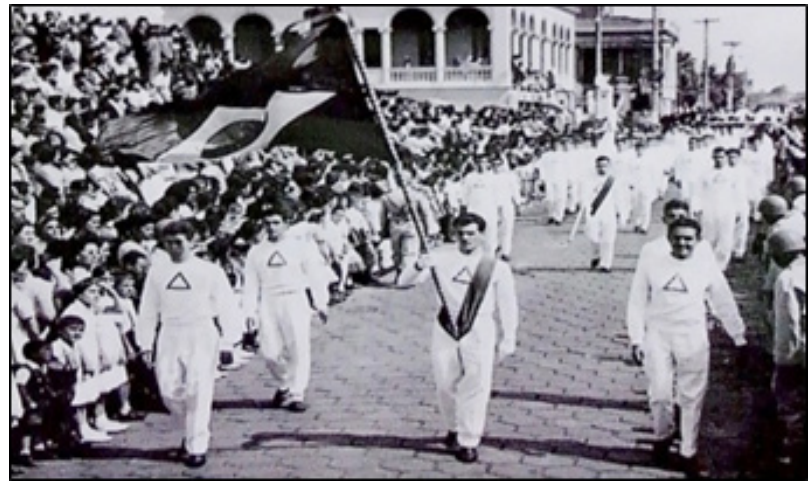

Fonte | Superintendência Regional de Ensino de Uberaba (Minas Gerais) 
As Figuras 5 e 6 apresentam a passagem das alunas do Colégio Triângulo Mineiro e mostram o uniforme que sobressaía pela cor branca, cuja camiseta era de manga curta, com saia longa, evidenciando-se ao centro a imagem de um triângulo, caracterizando, assim, a instituição. A elegância e postura das alunas também revelam o comportamento que elas deveriam ter diante da sociedade. Percebe-se que o público acompanhava os desfiles cívicos, o que evidencia que esses atos corroboravam um modo de socialização para a população uberabense. Esses eventos ainda tinham por objetivo mexer com o imaginário coletivo, visando legitimar os ideais do governo de então. A ideia era que todo esse espetáculo pudesse despertar nas pessoas um sentimento de compromisso e dever à pátria. Nessa perspectiva, a festa propaga e reflete um momento de confraternização, além de legitimar o poder e despertar o sentimento de amor à pátria.

Figura 5

Parada do Colégio Triângulo Mineiro - Rua Artur Machado com Av. Leopoldino de Oliveira [1950?]

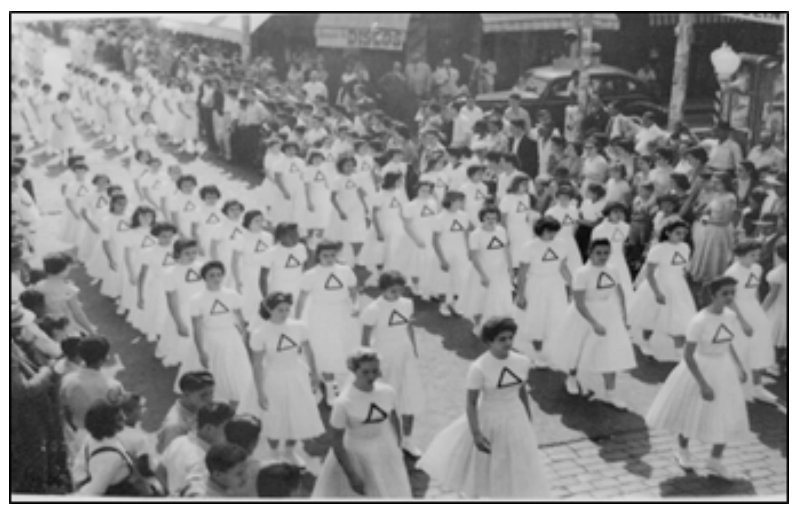

Fonte | Centro de Documentação Mário Palmério 


\section{Figura 6}

\section{Parada do Colégio do Triângulo Mineiro - Praça Rui Barbosa esquina com rua São Sebastião [1950?]}

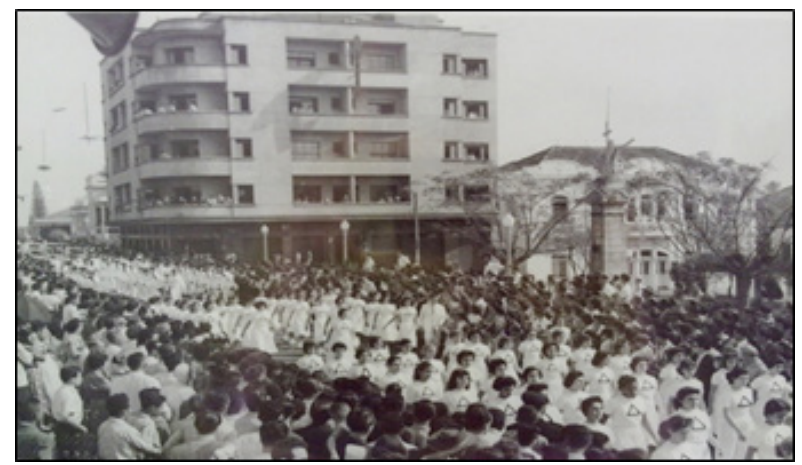

Fonte | Centro de Documentação Mário Palmério

\section{As práticas esportivas no Colégio Triângulo Mineiro}

A educação física, com o Estado Novo, passou a ser considerada obrigatória e se materializou a partir da Reforma Capanema em 1942 como prática educativa obrigatória. Por isso, na referida reforma, a educação física ganhou um espaço no documento em capítulo denominado "da educação física", que traz o seguinte teor em seu artigo 19:

A educação física constituirá uma prática educativa obrigatória para todos os alunos de curso diurno, até a idade de vinte e vinte e um anos. Parágrafo único: a educação física será ministrada segundo programas organizados e expedidos na forma do artigo anterior, nos próprios estabelecimentos, ou em centros especializados, que para esse fim se constituam lapud NÓBREGA, 1952, p. $316)$

Na perspectiva de Vargas, o cuidado com o corpo refletia-se à mente. Em seu discurso proferido em maio de 1940, destacou o seguinte:

[...] a educação do corpo, na mais ampla acepção da palavra, significa também o cultivo de nobres e excelentes atributos do espírito. [...] A agilidade, a destreza, a resistência muscular, estimulam 
e fortalecem aptidões intelectuais e a alta ascendência no desenvolvimento harmônico da personalidade [...] também adquire a firmeza nas decisões, a segurança de ação, o hábito salutar da disciplina consciente [...] (VARGAS, 1940, p. 31 1-312).

Constata-se, pela fala de Vargas a importância da atividade física como forma de manter não apenas o corpo em forma, mas também manter a mente sã, pois a mente precisa dessa estrutura corporal para se manter ativa e útil para servir à nação. O Decreto-Lei n².072, de 8 de março de 1940, em seu artigo $4^{\circ}$ destaca que,

A educação física, a ser ministrada de acordo com as condições de cada sexo, por meio da ginástica e dos desportos, terá por objetivo não somente fortalecer a saúde das crianças e jovens, tornando-os resistentes a qualquer espécie de invasão mórbida e aptos para os esforços continuados, mas também dar-thes ao corpo solidez, agilidade e harmonia. Paragráfo Único: Buscará ainda a educação física dar às crianças e jovens os hábitos e práticas higiênicas que tenham por finalidade aprevenção de toda a sorte de doenças, a conservação do bem estar e o prolongamento da vida. Será, neste particular, objeto de especial atenção o esclarecimento do papel que, na manutenção da saúde, desempenha a alimentação, e bem assim preceitos que sobre ela deveam ser continuamanete observados (BRASIL, 1940).

As atividades físicas eram destinadas a rapazes e moças, porém com o cuidado necessário em relação ao sexo feminino, visto que várias atividades não poderiam ser praticadas pelas mesmas, em função da delicadeza e fragilidade da mulher. De acordo com Foá,

A educação física da jovem não é somente para prepara-la para uma sádia maternidade física, mas fará dela uma mãe moralmente forte e corajosa, capaz de educar seus filhos. [...] A educação física faz, portanto, parte integrante da educação geral do indivíduo, contribuindo de modo eficaz e decisivo para formar a sáude física e moral do indivíduo, a saúde física e moral da nação (FOÁ, 1942, p. 2211.

Cabe destacar que o esporte também foi uma forma de propaganda política, uma vez que o governo de Vargas propunha uma ideia de formação moral, física e patriótica. Nesse sentido, o Colégio Triângulo Mineiro 
coadunava-se com essa política. De acordo com Fonseca (2010), Mário Pálmerio, por ser um entusiasta do esporte, acompanhava e se envolvia nas aulas e exibições de educação física. Fonseca (2010, p. 155) ainda enfatiza a narrativa do então diretor, "[...] viciá-los na educação física e no esporte. Ensiná-los a cuidar de seu corpo, supremo bem. Prepará-lo para a rudeza da vida, formando-o fisicamente, este seria o modelo de aluno formado no contexto da educação física. Assim, Fonseca (2010, p. 156) faz uma análise de que, na perspectiva da instrução secundária, o Colégio Triângulo Mineiro poderia ser considerado um triângulo, onde as suas vértices representavam "[... ] a educação moral, a educação intelectual e a educação física".

Dando ênfase à educação física por seu diretor Mário Palmério, o jornal Lavoura e Comércio, em 1944, trouxe a seguinte manchete sobre a instituição: "A maior realização de sentido educacional de todo interior do país", destacando a narrativa de seu diretor sobre a construção das piscinas no colégio:

As duas piscinas que se veem e que mal desmontados esses andaimes, serão iniciadas, são o que há de mais moderno. Esta, a grande, é de dimensões padronizadas, para competições oficiais. É a piscina conhecida como 'olímpica', cheia de majestade, com seu trampolim de 10 metros. Esta, a menor, isto é, bem mais estreita, é o 'cocho da aprendizagem', na gíria dos esportistas. Aqui aprende o aluno as suas primeiras lições na água e aqui ele permanece até que conheça perfeitamente bem os segredos da natação. Só então the é permitido passar para a maior. $\bigcirc$ 'cocho' é pouco profundo e tem o mesmo comprimento da piscina olímpica, o que afasta qualquer perigo de acidente e oferece as mesmas vantagens nos treinamentos de velocidade e resistência. A natação, como aliás, qualquer esporte, não pode ser praticada sem assistência técnica constante e competente. E essa assistência não faltará. [...] A natação é a 'cachaça' dos alunos aqui do ginásio. E eu, em vez de criar-thes embaraços, abro-lhes facilidades para praticá-la (A MAIOR REALIZAÇÃO DE SENTIDO EDUCACIONAL DE TODO INTERIOR DO PAÍS, 1944, p. 2).

Nessa perspectiva, percebe-se que o Colégio Triângulo Mineiro coadunava com as ideias propagadas pelo governo no período em questão. No caso do colégio, pode-se constatar o valor atribuído a essas questões pelo incentivo de seu diretor, Mário Palmério, pois as atividades físicas escolares 
desdobravam-se em atividades esportivas, agregadas aos eventos cívicos que aconteciam na cidade.

Em função desse apreço da direção da escola, o Colégio Triângulo Mineiro constituiu uma equipe de futebol masculino, uma equipe de vôlei feminino, que pertenciam ao colégio e que se destacavam nos eventos esportivos da cidade de Uberaba. Entre os anos de 1943 a 1959, os seus alunos participaram dos campeonatos com outras escolas. Fonseca, menciona que

Uma das ações que aparentemente mais entusiasmavam o diretor era o incentivo às práticas esportivas estudantis. Mário Palmério vez ou outra se manifestava sobre a importância que conferia à educação física na formação escolar. A propósito, o slogan da escola em 1943 era 'Uma perfeita educação intelectual ao par de uma completa educação física'. Pois bem, em geral, naquela época, as colunas de esporte da imprensa local noticiavam precisamente os torneios entre os times de colégios, associações e clubes recreativos. Foi nesse contexto que, no segundo semestre de 1942, Mário Palmério incentivou a criação do time de voleibol feminino e, a partir de então, as garotas do chamado 'six do Liceu' entraram animadas no circuito desportivo da cidade (FONSECA, 2012, p. 81.

A esse respeito, Souza (2008) aponta estudos sobre a vida nos ginásios e colégios do Brasil, mostrando que os desfiles cívicos, as passeatas, as confraternizações e as disputas esportivas foram atividades realizadas com maior intensidade pelos alunos no período de 1930 a 1960. A autora ressalta que essa gama de diversidade das práticas das escolas secundárias evidenciava a riqueza e variedade do conjunto universo das culturas escolares.

O relatório redigido por uma professora de Educação Física, do ano de 1956, corrobora a importância que era dada para essas atividades. Em relação às alunas, segundo a referida professora, elas eram preparadas, gradativamente, para a inserção nessas práticas:

Realizamos dois desfiles, nos quais nosso estabelecimento se destacou pelo brilhantismo e elegancia de nossas alunas. Procuramos cativar o enteresse, o gosto das alunas pela Educação Física e para isto introduzimos sempre que possível um jogo (RELATÓRIO..., 1956, s/p). 
Figura 7

Mário Palmério e a equipe de vôlei do Colégio Triângulo Mineiro [1950?]

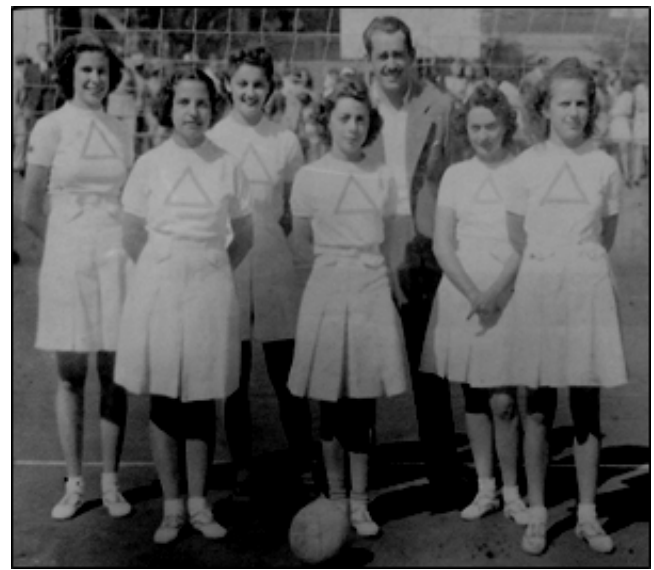

Fonte | Centro de Documentação Mário Palmério

As meninas do voleibol feminino do colégio entraram para o circuito desportivo da cidade e mobilizavam a participação da sociedade da época, imprimindo mais prestígio à escola e à figura de seu diretor Mário Palmério. Em 1959, foi publicada matéria sobre a equipe feminina de vôlei do Colégio Triângulo Mineiro, que ganhou campeonato contra as alunas da Escola Normal. Não foi citado, pelo jornal, o nome da Escola Normal. Apesar de não ser possível afirmar se as alunas que aparecem, na Figura 7, eram as que o jornal divulgou em 24/4/1959, cabe ressaltar que, nessa data, a instituição de Mário Palmério foi vencedora na disputa. Assim, o jornal relatava:

Mais um triunfo do Triangulo - No encontro numero dois, as moças do Colegio do Triangulo venceram com justiça as 'estrelas' da Escola Normal por 2xO. Foi um jogo fraco tecnicamente e falho na parte conjuntiva. Pela maior categoria de algumas integrantes do Triangulo pode-se dizer que ficou bem a vitoria das pupilas da professora Helice Ferreira. Os 'sets' foram de 15x6 e 15x7. Magoga e Edison foram os juizes. Os dois quadros estiveram assim representados: TRIANGULO: Darci, Lidia, Neide, Dalva, Maria Ivone, Marilene, Mariza, Zilda e Sandra. NORMAL: Nilza, Edna, Antonia, Romilda, Glorinha, Marília e Vania IMAIS UM TRIUNFO DO TRIÂNGULO, 1959. s/p). 
Em outro recorte de jornal encontrado na Superintendência Regional de Ensino de Uberaba, com a data de 15 setembro de 1959, havia uma referência às olimpíadas entre as escolas. Sem identificação do nome do veículo de comunicação, o recorte trazia a manchete estampada em letras maiúsculas, destacando o evento: "OLIMPIADAS COLEGIAIS: TRIÂNGULO, CRISTO-REI E MAGISTERIO OS VENCEDORES DE ONTEM". Dessa forma, o jornal detalhava:

FORAM os seguintes, os resultados da $2^{a}$ rodada das olimpíadas Ginásio-Colegiais, realizada ontem: ATLETISMO - local UTC -75 metros - juvenil feminino: Silvia Garcia, com 1 1'2 -(Col. Triangulo); Rosa Crosara com 1 1',4 do Triangulo; Lilia S. Almeida 1 1', 5 do Colégio Cristo Rei, 100 metros rasos - rapazes: 1) Celso R. da Cunha (Triangulo) 12'2;2) Divino (Triangulo) 12',6;3) Valter V. Silva (Cristo Rei) 12'8.75 metros juvenil - masculino: Aparecido A. Cruz (Senai) 9', 8 - Rubens Staciarini (C.Rei) 10',O; Heitor A. Pinto (Triangulo) 10'1 e Hely Silva (Senai) 10'11(OLIMPÍADAS COLEGIAIS..., IOLIMPIADAS COLEGIAIS: TRIÂNGULO, CRISTO REI E MAGISTERIO OS VENCEDORES DE ONTEM, 1959, s/p).

Verifica-se, desse modo, que o Colégio Triângulo Mineiro obteve 206 destaque tanto em eventos cívicos quanto esportivos e isso contribuiu para enfatizar o papel da instituição como exemplo de boa conduta, não só aos alunos como também para a sociedade, e como colaboradora para a manutenção da ordem no país e o desenvolvimentos de hábitos salutares, além de reforçar a identidade da instituição.

\section{Considerações finais}

Ao analisar os eventos cívicos escolares, verifica-se que essas atividades faziam parte do calendário escolar. Além dos conteúdos a serem apreendidos, as atividades cívicas e esportivas tinham um espaço especial no contexto da escola, incorporado a outros elementos da chamada cultura escolar.

Esses rituais, levados para fora dos portões da escola, ajudavam a construir não apenas a identidade da escola, mas também reforçar a importância dos símbolos nacionais. Essas manifestações eram carregadas de 
simbolismo e significações que contribuíam para a construçãoda ideia de Estado Nacional.

No que se refere às ações do Colégio Triângulo Mineiro, é perceptível a incorporação desses valores patrióticos e esportivos, pela forma como a imprensa noticiava tais eventos. Tanto as festividades cívicas quanto os eventos esportivos eram divulgados com tamanha pompa, enaltecendo a juventude que, naquele momento, era o centro das atenções.

jornal Lavoura e Comércio enfatizava a importância do respeito e amor à nação, atribuindo uma significação tão forte para tais atividades a ponto de detalhar inclusive a programaçãoque seria apresentada durante a semana em comemoração à pátria.

Ressaltava a imponênciado evento e o compromisso que todos os cidadãos deveriam ter para com a festividade. $\bigcirc$ veículo reforçava, ainda, as dimensões políticas e patrióticas, legitimando a importânciada ordem e a civilidade no Brasil. Em outras palavras, a imprensa ajudava a reforçar esses princípios cívicos, que ajudam a construir um novo sujeito social, o que era imprescindivel para o contexto histórico da época.

Além disso, as festas cívicas e esportivas tinham, sobretudo, um caráter de propaganda política, haja vista a estratégia de valorizar o governo da época, buscando reforçar a ideia de patriotismo e de defesa da nacionalidade.

Assim, esses eventos buscavam, por meio da juventude, consolidar os ideais políticos de época, mostrando a importância da disciplina e da ordem evidenciando os deveres e obrigações para com a pátria. Certamente, o Colégio Triângulo Mineiro contribuiu para a disseminação desses valores e do espírito de patriotismo na sociedade uberabense.

É interessante destacar que, mesmo que os alunos não percebessem a significação desses símbolos nacionais apresentados em festividades cívicas, eles acabavam deixando-se levar pela celebração e, de alguma forma, conseguiam partilhar desse espírito de civismo. Em síntese, pode-se afirmar que as festividades além de movimentarem a cidade, também visavam à a perpetuação de um ideal político, ou seja, disseminar sentimentos patrióticos, alinhados aos ideais de Estado e construindo uma identidade coletiva.

Sem dúvida, as práticas escolares, desenvolvidas no âmbito do Colégio Triângulo de Uberaba, estavam em perfeita consonância com o ideário político vigente à época. Essas práticas escolares, efetivamente, colaboravam 
para a legitimação desse ideário cívico e patriótico, seja na mente e nos corações dos alunos, seja no âmbito das famílias a que pertenciam esses alunos, e, ainda, junto às pessoas que habitavam a cidade nas décadas de 1940 e 1950.

\section{Referências}

A MAIOR realização de sentido educacional de todo interior do país. Lavoura e Comércio, Uberaba, p. 2, 14 jul. 1944.

BRASIL. Decreto-Lei $\mathbf{n}^{\circ} \mathbf{2 . 0 7 2}$, de 8 de março de 1940. Dispõe sobre a obrigatoriedade da educação cívica, moral e física da infância e da juventude, fixa as suas bases, e para ministrá-la organiza uma instituição nacional denominada Juventude Brasileira. Disponível em: $\quad$ http://www2.camara.leg.br/legin/fed/declei/1940-1949/decreto-lei-2072-8-marco-1940-41 21 103-publicacaooriginal-7-pe.html. Acesso em: 15 out. 2015.

BRASIL. Presidência da República. Decreto n ${ }^{\circ}$ 21.901, de 7 de outubro de 1946. Concede reconhecimento ao curso ginasial do Ginásio do Triângulo Mineiro, de Uberaba. Disponível em: $\quad$ http://legis.senado.gov.br/legislacao/ListaTextolntegral. action?id= 133041 \& norma $=154660$. Acesso em: 10 out. 2015.

208 BRASIL. Presidência da República. Decreto n 22.523, de 27 de janeiro de 1947. Autoriza o Ginásio de Triângulo Mineiro, com sede em Uberaba, no Estado de Minas Gerais, a funcionar como colégio. Disponível em hitp://legis.senado.gov.br/legislacao/ListaTexto Integral. action?id=133486\&norma=155108. Acesso em: 15 out. 2015.

CANDIDO, Renata Marcilio. Culturas da escola: as festas nas escolas públicas paulistas (1889-1930). 2007. 154f. Dissertação (Mestrado em Educação) - Programa de PósGraduação em Educação da Universidade de São Paulo. São Paulo. 2007. Disponível em: http://www.teses.usp.br/teses/disponiveis/ 48/48134/tde-29012008-163237/pt-br. php. Acesso em: 10 out. 2015.

COLÉGIO Triângulo Mineiro. Acervo fotográfico. Uberaba (1943 a 1956). (Centro de Documentação Mário Palmério).

DA MATTA, Roberto. Carnavais, malandros e heróis (para uma sociologia do dilema brasileiro). Rio de Janeiro: Guanabara, 1997.

FOÁ, Carlo. $\bigcirc$ ensino da fisiopatologia para professores e médicos especializados em educação física. CONGRESSO PAULISTA DA EDUCAÇÃO FíSICA, 1, São Paulo. Anais...São Paulo: Associação de Professores de Educação Física (APEF), 1942. 
FONSECA, André Azevedo da. A consagração do mito Mário Palmério no cenário político do Triângulo Mineiro (1940-1950). 2010. 335f. Tese (Doutorado em História) - Programa de Pós-Graduação em História da Universidade Estadual Paulista "Júlio de Mesquita Filho". Franca (São Paulo) 2010. Disponível em: http://repositorio.unesp.br/bitstream/handle/1 1449/103080/fonseca_aa_dr_fran.pdf?̨sequence=1 \&isAllowed=y. Acesso em: 10 out. 2015 .

FONSECA, André Azevedo da. Imagem e representação social do professor Mário Palmério na imprensa mineira dos anos 1940. In: CONGRESSO DA COMUNICAÇÃO NA REGIÃO SUL, 13; 201 2, Chapecó. Anais... Chapecó: Sociedade Brasileira de Estudos Interdisciplinares da Comunicação, Regional Sul. 2012. Disponível em: http://www.intercom.org.br/papers/regionais/sul2012/resumos/R30-0875-1.pdf. Acesso em: 10 out. 2015.

GATTI, Giseli Cristina do Valle. Tempo de cidade, lugar de escola: dimensões do ensino secundário no Gymnásio Mineiro de Uberlândia (1929-1950). 2010. 270 f. Tese (Doutorado em Educação) Programa de Pós-Graduação em Educação da Universidade Federal de Uberlândia, 2010. Disponível em: http://repositorio.ufu.br/bitstream/123456789/3487/1/ TempoCidadelugar. pdf. Acesso em: 15 out. 2015.

JULIA, Dominique. A cultura escolar como objeto histórico. Revista Brasileira de História da Educação, Campinas, n. 1, p. 9-44, 2001.

MAGALHÃES, Justino. Contributo para a história das instituições educativas - entre a memória e o arquivo. In: FERNANDES, Rogério; MAGALHÃES, Justino (Org.). Para a história do ensino liceal em Portugal. Actas dos Colóquios do I Centenário da Reforma de Jaime Moniz (1894-1895). Braga: Universidade do Minho, 1999, p. 63-77.

MAIS UM Triunfo do Triângulo. Lavoura e Café, Uberaba, s. p. 24 abr. 1959.

MINAS GERAIS. Superintendência Regional de Ensino de Uberaba. Colégio Triângulo Mineiro. Acervo Fotográfico. Uberaba (1943- 1956).

NÓBREGA, Vandick Lopes. Enciclopédia da legislação do ensino. Rio de Janeiro, 1952.

OLIMPIADAS Colegiais: Triângulo, Cristo-Rei e Magisterio os vencedores de ontem. Lavoura e Comércio, Uberaba, s/p. 15 set. 1959.

RELATÓRIO da professora de Educação Física. Uberaba, 1956. (Superintendência Regional de Ensino de Uberaba).

SCHEMES, Cláudia. Festas cívicas e esportivas no populismo: um estudo comparativo dos governos Vargas (1937-1945) e Peron (1946-1955). 168fls 1995. Dissertação (Mestrado em História) - Programa de Pós-Graduação em História. Universidade de São Paulo, São Paulo. 1995. 
A educação para o civismo e o patriotismo no Colégio Triângulo Mineiro de Uberaba nas décadas de 1940 e 1950

SOUZA, Rosa Fátima de. História da organização do trabalho escolar e do currículo no século XX (ensino primário e secundário). São Paulo: Cortez, 2008.

O ANIVERSÁRIO do Liceu Triangulo Mineiro. Lavoura e Comércio. s/p. 19 jul. 1943.

COMO Uberaba comemorou o Dia da Patria. Lavoura e Comércio. p. 2, 08 set. 1941.

UBERABA comemorou de modo brilhante o Dia da Pátria, realizando sessões cívicas e briIhantes paradas pelas ruas da cidade. Lavoura e Comércio, Uberaba, p. 6.8 set. 1941).

UBERABA vive hoje um de seus mais gloriosos dias cívicos. Lavoura e Comércio, Uberaba, p. 1, 7 set. 1942.

VARGAS, Getúlio. A nova política no Brasil. No limiar de uma nova era (20/10/1939 a 29/06/1940). Rio de Janeiro: José Olimpio, 1940.

VAZ, Aline Choucair. A escola em tempos de festa: poder, cultura e práticas educativas no Estado Novo (1937-1945). 2006. 131 f. Dissertação (Mestrado em Educação) - Programa de Pós-Graduação em Educação da Universidade Federal de Minas Gerais, Belo Horizonte, 2006. Disponível em: http://www.fae.ufmg.br/portalmineiro/conteudo/hiseduminas/disserts/disser_alinechoucair.pdf. Acesso: em 10 out. 2015.

Ms. Edilene Alexandra Leal Soares Universidade Federal do Triângulo Mineiro Pró-Reitoria de Assuntos Comunitários e Estudantis Grupo de Estudos e Pesquisas em História e Historiografia da Educação Brasileira E-mail | edilenealexandra@yahoo.com.br

Profa. Dra. Giseli Cristina do Valle Gatti Universidade de Uberaba

Programa de Pós-Graduação em Educação Beneficiária do Edital Universal da Fapemig Grupo de Estudos e Pesquisas em História e Historiografia da Educação Brasileira E-mail | giseli.vale.gatti@gmail.com

Recebido 28 jul. 2016 Aceito 14 nov. 2016 